\title{
Avaliação de temperaturas em câmaras frigoríficas de transporte urbano de alimentos resfriados e congelados
}

\author{
Evaluation of temperatures in a refrigerated container for chilled and frozen food transport
}

\author{
Vítor de Freitas PEREIRA²*, Eduardo Castello Branco DORIA ${ }^{2}$ Bento da Costa CARVALHO JÚNIOR², \\ Lincoln de Camargo NEVES FILHO ${ }^{2}$, Vivaldo SILVEIRA JÚNIOR ${ }^{2}$
}

\begin{abstract}
Resumo
O objetivo deste trabalho foi monitorar as condições operacionais do transporte frigorificado urbano de alimentos resfriados e congelados durante as entregas dos produtos e avaliar a influência das aberturas das portas da câmara nas alterações das temperaturas internas do ambiente frigorificado. Instrumentou-se uma câmara frigorífica bipartida do tipo $3 / 4$ com sensores de temperatura e pressão, que foram instalados em pontos específicos no sistema de refrigeração e nas superfícies internas e externas da câmara do caminhão. Após as monitorações, foi verificado que as aberturas de portas no momento das entregas resultaram na elevação da temperatura interna da câmara acima dos valores recomendados para a conservação adequada dos produtos transportados, além de que o aumento no número de aberturas de porta provocou um efeito acumulativo de aumento da temperatura interna, principalmente no compartimento de resfriados. Concluiu-se que o sistema de refrigeração utilizado pela frota de caminhões da empresa que produziu os alimentos transportados apresenta limitações quanto à manutenção da temperatura interna da câmara durante a rotina real de distribuição, pois não possui capacidade instantânea suficiente para retomar a temperatura adequada entre as entregas.
\end{abstract}

Palavras-chave: alimentos; câmara; congelados; instrumentação; resfriados; transporte.

\begin{abstract}
The objective of this work was to monitor the operational conditions of the transport of chilled and frozen foods during delivery within cities and to evaluate the impact of the door openings on the alteration of the internal temperature of the refrigerated environment. Several temperature and pressure sensors were used in a refrigerated container with two compartments and they were installed in the refrigeration system unit and on the internal and external surfaces of the container. After the monitoring tests, it was verified that door openings during deliveries resulted in a disturbance that raised the internal temperature of the refrigerated container above values recommended for adequate conservation of the products transported. Moreover, increasing the number of door openings promoted a cumulative effect on the internal temperature, mainly in the chilled food compartment of the container. It was concluded that the refrigeration system unit presented serious limitations with regard to the maintenance of the container's internal temperature during the actual distribution routine, since it does not possess enough instantaneous capacity to restore the temperature set-point between deliveries.

Keywords: chilled; container; food; frozen; instrumentation; transport.
\end{abstract}

\section{Introdução}

A cadeia do frio compreende todo processo de armazenamento, conservação, distribuição, transporte e manipulação dos produtos, com o controle da baixa temperatura. Qualquer falha nesta cadeia pode comprometer a qualidade dos produtos, pois as velocidades das reações químicas, bioquímicas e microbiológicas são relacionadas diretamente com a temperatura, influenciando a sanidade, a qualidade nutricional e a qualidade sensorial dos produtos refrigerados. Portanto, manter uma cadeia do frio intacta, operando com temperaturas corretas desde o produtor até o consumidor final, é essencial (IIR, 2004).

A perda de qualidade do produto é cumulativa e irreversível, o que ressalta a necessidade de se manter a temperatura baixa do produto transportado ao longo de toda a cadeia do frio (HEAP; KIERSTAN; FORD, 1998).
É senso comum que, durante o transporte de alimentos resfriados e congelados, quanto mais longo for o deslocamento maior deverá ser o cuidado para evitar o rompimento da cadeia do frio. Infelizmente, tem-se a ideia de que o inverso é verdadeiro, ou seja, se os deslocamentos são curtos durante as entregas destes produtos, não existe a necessidade de se preocupar com o rompimento da cadeia do frio. Este raciocínio faz com que os deslocamentos curtos sejam os mais críticos para a manutenção da cadeia do frio (HEAP, 2006).

Os produtos a serem transportados devem, obrigatoriamente, ter suas temperaturas reduzidas antes de entrarem na câmara (HEAP, 2006), pois o sistema de refrigeração utilizado para o transporte de alimentos resfriados e congelados não é dimensionado para reduzir a temperatura destes produtos (IIR, 2006). O sistema de refrigeração de câmaras é dimensionado

${ }^{1}$ Transfrigor do Brasil Indústria e Comércio de Equipamentos de Refrigeração para Transportes Ltda. (Diretoria), CEP 13070-780 Campinas - SP, Brasil

${ }^{2}$ Departamento de Engenharia de Alimentos, Universidade Estadual de Campinas, Campinas - SP, Brasil, E-mail: vfpereira@gmail.com

${ }^{*}$ A quem a correspondência deve ser enviada 
para somente manter a baixa temperatura dos produtos transportados, de modo que, para ser utilizado com o intuito de reduzir a temperatura do produto durante o transporte, o sistema de refrigeração precisaria ter uma capacidade muito maior do que a normalmente empregada (MERCANTILA, 1989).

Segundo a NBR 14701 (ABNT, 2001), deve-se, obrigatoriamente, reduzir e estabilizar a temperatura interna da câmara por pelo menos 15 minutos antes da entrada do produto alimentício. É necessária também a utilização de instrumentos para registro contínuo da temperatura do ar interno durante o transporte.

Os momentos de carregamento e descarregamento dos produtos resfriados e congelados podem ser os mais críticos para o rompimento da cadeia do frio se estas etapas não forem realizadas rapidamente (IIR, 2006). Cada abertura de porta da câmara para transporte provoca a troca do ar refrigerado pelo ar quente e úmido do ambiente externo (IIR, 1986). As portas da câmara devem ficar abertas somente o necessário durante as entregas, devendo ser fechadas o mais rápido possível (HIRA, 2001).

O equipamento de refrigeração não possui capacidade instantânea suficiente para retirar a carga térmica proveniente da entrada do ar quente do ambiente externo entre uma abertura e outra durante as entregas. É essencial, assim, que a entrada de ar do ambiente externo seja evitada ao máximo, reduzindo-se o tempo e o número de abertura das portas (TRESSLER, 1968).

Quando as aberturas da porta são frequentes, há formação de gelo no evaporador, reduzindo o desempenho do sistema de refrigeração e aumentando a necessidade da realização de degelos, especialmente em ambientes com umidade relativa alta (ESTRADA-FLORES; EDDY, 2006). O gelo formado dificulta a troca de calor entre a superfície da serpentina e o ar circulado pela câmara, podendo, inclusive, bloquear totalmente a sua passagem pela serpentina (NEVES FILHO, 2004).

Durante o carregamento/descarregamento dos produtos na câmara, o sistema de refrigeração deve estar desligado, tendo em vista que isto diminui o gasto de combustível e evita uma maior necessidade da realização de degelos (HIRA, 2001), pois, com os ventiladores do evaporador desligados, existe uma menor substituição do ar frio do ambiente interno pelo ar quente e úmido do ambiente externo.

A literatura consultada confirmou a necessidade de se verificar o efeito da entrada de carga térmica no ambiente refrigerado de câmaras frigoríficas durante o transporte de produtos resfriados/congelados. Sendo assim, este trabalho visou compreender o processo de distribuição destes produtos nos centros urbanos, avaliando a influência das aberturas das portas da câmara na alteração da temperatura interna do ambiente frigorificado. Para isto, foi feita a monitoração das práticas operacionais adotadas ao longo do processo de distribuição, com o veículo comercial em trânsito e durante as entregas urbanas.

\section{Material e métodos}

Para o levantamento, em campo, das condições operacionais reais do transporte frigorificado de produtos resfriados e congelados, contou-se com a colaboração de uma empresa de grande porte fabricante de alimentos que possui fábricas em várias regiões do País.

A monitoração do transporte foi realizada durante os meses de agosto e setembro de 2007 no Estado de São Paulo, onde o transporte frigorificado está bastante consolidado, abrangendo as seguintes cidades do interior do estado: Águas de São Pedro, Americana, Araras, Iracemápolis, Piracicaba, Rio Claro, Santa Bárbara e Sorocaba. O acompanhamento do transporte de produtos resfriados e congelados foi feito desde o centro de distribuição da empresa produtora dos alimentos até os estabelecimentos comerciais, monitorando-se as condições de transporte durante todo o trajeto.

O caminhão utilizado durante a monitoração era da marca Volkswagen, modelo 8150 movido a diesel (143 cv) e pertencia à frota de transporte da empresa fabricante dos alimentos. Era dotado de uma câmara frigorífica da empresa Litocargo, a qual tinha 5,0 m de comprimento, 2,2 m de largura e 2,3 m de altura. Ela possuía dois compartimentos e uma divisória fixa, pintada externamente na cor branca. Um compartimento era destinado para os produtos resfriados e outro para os congelados. A câmara era constituída por painéis tipo "sanduíche" de densidade média de $40 \mathrm{~kg} \cdot \mathrm{m}^{-3}$, com lâminas de fibra de vidro e recheio de poliuretano. As paredes, o teto e o piso da câmara possuíam $100 \mathrm{~mm}$ de espessura e o volume interno da câmara era de $20,2 \mathrm{~m}^{3}$.

$\mathrm{O}$ equipamento de refrigeração instalado na câmara era da marca Transfrigor, modelo TF6.4-RB MAXi, e utilizou o refrigerante R404A. O funcionamento deste sistema de refrigeração foi possível por meio do uso de um compressor acoplado ao eixo do motor do caminhão. Assim, conforme a rotação do eixo do motor variava, uma mudança na rotação do eixo do compressor acoplado também era observada. O compressor era da marca Sanden, modelo SD7H15, com 7 pistões, deslocamento fixo total de $154,7 \mathrm{~mL}$ e rotação máxima de $6000 \mathrm{rpm}$.

No compartimento de produtos resfriados foram utilizados 11 sensores de temperatura da marca Testo, modelo T-175-H1, os quais eram sensores do tipo NTC e possuíam capacidade de armazenamento de até 3700 dados, podendo operar dentro da faixa de -10 a $+50{ }^{\circ} \mathrm{C}$. Os sensores foram distribuídos da seguinte maneira:

- Três na parede lateral esquerda (lado do motorista):

- um a $3 \mathrm{~cm}$ do teto e a $3 \mathrm{~cm}$ da superfície traseira;

- um a $3 \mathrm{~cm}$ do piso e a $3 \mathrm{~cm}$ da superfície traseira; e - um no centro da parede lateral esquerda do compartimento.

- Três na parede lateral direita (lado do copiloto):

- um a $3 \mathrm{~cm}$ do teto e a $3 \mathrm{~cm}$ da superfície traseira;

- um a $3 \mathrm{~cm}$ do piso e a $3 \mathrm{~cm}$ da superfície traseira; e

- um no centro da parede lateral direita do compartimento. 
- Um foi colocado na divisória da câmara, a $3 \mathrm{~cm}$ do piso e a $3 \mathrm{~cm}$ da porta, próximo à parede lateral direita.

- Um foi colocado no centro do teto do compartimento.

- Três foram posicionados próximos à porta de acesso ao ambiente externo:

- um a $3 \mathrm{~cm}$ da porta e a $1 \mathrm{~m}$ do teto, próximo à parede lateral direita;

- um a $3 \mathrm{~cm}$ da porta e a $1 \mathrm{~m}$ do teto, próximo à parede lateral esquerda; $\mathrm{e}$

- um sobre a porta, a $3 \mathrm{~cm}$ desta e equidistante das paredes laterais.

Um termopar do tipo $\mathrm{K}$ foi instalado próximo à porta de acesso ao ambiente externo com o intuito de identificar os momentos de abertura da porta durante as entregas dos produtos nos estabelecimentos comerciais. Quando a porta era aberta, a massa de ar quente proveniente do ambiente externo provocava um aumento brusco de temperatura no elemento sensor do termopar ao entrar em contato com ele. Neste momento, o termopar enviava um sinal para um data-logger instalado na superfície interna traseira do compartimento, ao qual estava conectado, que associava o momento da aquisição do sinal com o horário, proporcionando, desta forma, a análise gráfica posterior dos momentos das aberturas. O data-logger utilizado era da marca Testo do Brasil, modelo T-177-T4, com 4 canais e capacidade para armazenar 48000 valores.

No compartimento de congelados foram instalados 14 sensores de temperatura da marca Testo, sendo 11 do modelo T-175-H2, os quais eram sensores do tipo NTC e possuíam capacidade de armazenamento de até 16000 dados, podendo operar dentro da faixa de $-20 \mathrm{a}+70^{\circ} \mathrm{C}$, e 3 do modelo T-175-H1. Os sensores foram instalados da seguinte maneira:

- Três na parede lateral esquerda (lado do motorista):

- um a $3 \mathrm{~cm}$ do teto e a $3 \mathrm{~cm}$ da superfície frontal;

- um a $3 \mathrm{~cm}$ do piso e a $3 \mathrm{~cm}$ da superfície frontal; e

- um no centro da parede lateral esquerda do compartimento.

- Três na parede lateral direita (lado do copiloto):

- um a $3 \mathrm{~cm}$ do teto e a $3 \mathrm{~cm}$ da superfície frontal;

- um a $3 \mathrm{~cm}$ do piso e a $3 \mathrm{~cm}$ da superfície frontal; e

- um no centro da parede lateral direita do compartimento.

- Um foi colocado na divisória da câmara, a $3 \mathrm{~cm}$ do piso e a $3 \mathrm{~cm}$ da porta, próximo à parede lateral direita.

- Um foi colocado no centro do teto do compartimento.

- Dois foram posicionados próximos à porta de acesso ao ambiente externo:

- um a $3 \mathrm{~cm}$ da porta e a $1 \mathrm{~m}$ do teto, próximo à parede lateral direita; $\mathrm{e}$
- um a $3 \mathrm{~cm}$ da porta e a $1 \mathrm{~m}$ do teto, próximo à parede lateral esquerda.

- Dois para o ar de retorno, posicionados sobre a parede frontal:

- um a $1 \mathrm{~m}$ do piso e equidistante das paredes laterais; e

- um a $3 \mathrm{~cm}$ do teto e equidistante das paredes laterais.

- Dois para o ar de insuflamento, posicionados no evaporador próximos à saída de ar:

- um a $20 \mathrm{~cm}$ da extremidade esquerda do evaporador; e

- um a $20 \mathrm{~cm}$ da extremidade direita do evaporador.

Um termopar do tipo $\mathrm{K}$ também foi instalado próximo à porta interna com o intuito de identificar os momentos de abertura da porta durante as entregas dos produtos. O termopar estava conectado a outro data-logger, do mesmo modelo do que foi utilizado no compartimento de resfriados.

Externamente, a câmara foi instrumentada com 10 termopares do tipo $\mathrm{K}$, os quais estavam conectados a data-loggers modelo T-177-T4 da marca Testo do Brasil. Os sensores foram instalados da seguinte maneira:

- Dois foram colocados no teto, equidistantes das superfícies frontal e traseira. Um a $50 \mathrm{~cm}$ da superfície lateral esquerda e um a $50 \mathrm{~cm}$ da superfície lateral direita.

- Dois foram colocados na superfície lateral esquerda (lado do motorista), equidistantes do teto e do piso. Um a $1 \mathrm{~m}$ da superfície frontal e um a $1 \mathrm{~m}$ da superfície traseira.

- Um foi colocado na superfície lateral direita (lado do copiloto), equidistante do teto e do piso e a $1 \mathrm{~m}$ da superfície frontal.

- Dois foram colocados sob o piso, equidistantes da superfície lateral esquerda e da superfície lateral direita. Um a $1 \mathrm{~m}$ da superfície frontal e um a $1 \mathrm{~m}$ da superfície traseira.

- Dois foram colocados sobre a superfície traseira a $3 \mathrm{~cm}$ da extremidade superior da porta. Um a $50 \mathrm{~cm}$ da superfície lateral esquerda e um a $50 \mathrm{~cm}$ da superfície lateral direita.

- Um foi colocado na superfície frontal, equidistante da superfície lateral esquerda e da superfície lateral direita e a $1 \mathrm{~m}$ do piso.

Da Figura 1 a Figura 5 estão ilustrados os pontos de instalação dos sensores de temperatura na câmara do caminhão.

O sistema de refrigeração foi instrumentado com sensores de temperatura (termopar tipo K) e com sensores de pressão (1 a 40 bar). Um termopar foi instalado na seção frontal do condensador para medir a temperatura do ar de resfriamento antes de este passar pelo condensador (ar ambiente). Outro termopar foi instalado na seção posterior do condensador para medir a temperatura do ar de resfriamento após a sua passagem pelo condensador (ar aquecido). 


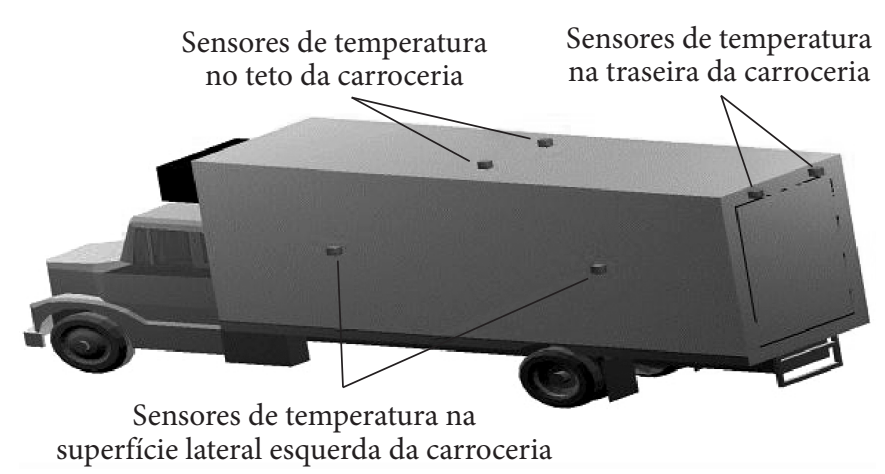

Figura 1. Sensores de temperatura nas superfícies externas da câmara frigorífica (lateral esquerda, teto e traseira).

Sensor de temperatura na Sensor de temperatura na superfície superfície frontal da carroceria lateral direita da carroceria

Figura 2. Sensores de temperatura nas superfícies externas da câmara frigorífica (lateral direita, piso e frontal).

\section{Sensores de temperatura no teto do compartimento de congelados}

Sensores de temperatura no teto do

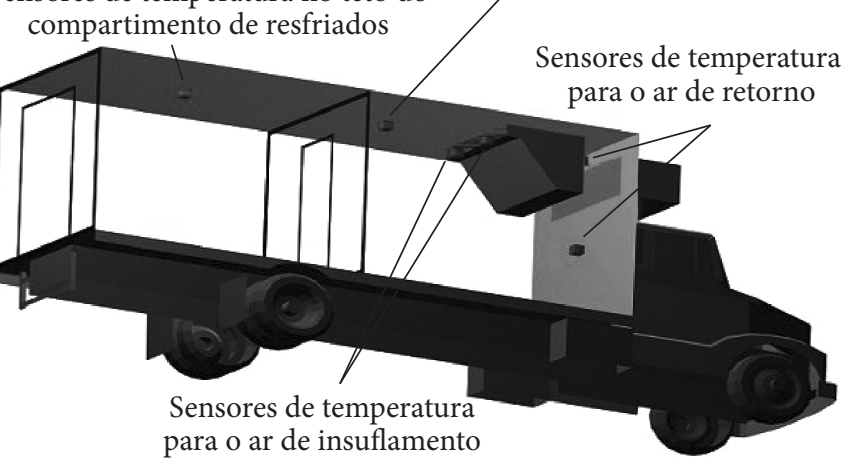

Figura 3. Sensores de temperatura no teto da câmara frigorífica e próximos ao evaporador.

Foram instalados termopares tipo $\mathrm{K}$ na superfície da tubulação que leva o refrigerante da saída do condensador para a garrafa de líquido, logo após a válvula de expansão do evaporador, e na linha de sucção do compressor acoplado ao motor do caminhão. Todos estes termopares estavam conectados a dois data-loggers da marca Testo do Brasil, modelo
T-177-T4. Um data-logger foi instalado na superfície externa frontal da câmara, abaixo da unidade condensadora e o outro foi instalado no compartimento do motor do caminhão, próximo ao compressor acoplado.

Os sensores de pressão foram instalados em três pontos: na linha de sucção do compressor acoplado; na saída do condensador antes da entrada da garrafa de líquido; e após a válvula de expansão. Em todos os pontos os sensores de pressão foram conectados ao sistema de refrigeração pelas válvulas Schrader presentes nas linhas. Estas válvulas, normalmente utilizadas nos pneus dos veículos automotivos, quando estão em posição normal permanecem fechadas devido à ação de uma mola que pressiona o obturador sobre um ressalto interno, impedindo a saída de refrigerante. Os sensores de pressão, ao serem conectados às válvulas, pressionaram o obturador interno, abrindo-as. Os sensores de pressão enviavam os sinais para um data-logger marca Testo do Brasil, modelo 350/454, com capacidade para 500000 valores, presente dentro da cabine do caminhão.

\section{Resultados e discussão}

Foram realizados sete monitoramentos diários referentes às variações de temperatura dos ambientes interno e externo da câmara e às variações de temperatura e pressão do sistema de refrigeração.

A Tabela 1 mostra os resultados obtidos durante os sete dias de monitoração.

No quarto e no sétimo dia de monitoração, a duração da maioria das entregas foi curta (média do $4^{\circ}$ dia $=4,88$ minutos e média do $7^{\circ}$ dia $=3,85$ minutos) e elas eram iniciadas logo que a anterior era finalizada. A minoria das entregas nestes dias foi de maior duração, quando no quarto dia foi observada

Tabela 1. Número e duração das entregas e das paradas do motor; número de degelos e tempo de retomada de temperatura após o término das entregas de cada dia monitorado

\begin{tabular}{|c|c|c|c|c|c|c|c|}
\hline Dia monitorado & $1^{\circ} \mathrm{dia}$ & $2^{\circ} \mathrm{dia}$ & $3^{\circ}$ dia & $4^{\circ} \mathrm{dia}$ & $5^{\circ}$ dia & $6^{\circ}$ dia & $7^{\circ} \mathrm{dia}$ \\
\hline Entregas & 4 & 5 & 4 & 28 & 2 & 3 & 14 \\
\hline Média (minutos) & 20,50 & 13,60 & 23,25 & 4,88 & 47 & 35,33 & 3,85 \\
\hline Mediana (minutos) & 19,50 & 5 & 24 & 2,95 & 47 & 13 & 4,13 \\
\hline $\begin{array}{l}\text { Desvio padrão } \\
\text { (minutos) }\end{array}$ & 13,82 & 17,67 & 16,54 & 6,42 & 32,53 & 43,09 & 2,57 \\
\hline $\begin{array}{l}\text { Valor mínimo } \\
\text { (minutos) }\end{array}$ & 5 & 1 & 7 & 0,25 & 24 & 8 & 0,17 \\
\hline $\begin{array}{l}\text { Valor máximo } \\
\text { (minutos) }\end{array}$ & 38 & 44 & 38 & 30,83 & 70 & 85 & 8,25 \\
\hline $\begin{array}{l}\text { Erro padrão } \\
\text { (minutos) }\end{array}$ & 6,91 & 7,90 & 8,27 & 1,20 & 23 & 24,88 & 0,70 \\
\hline Número de degelos & 4 & 3 & 4 & 5 & 1 & 1 & 3 \\
\hline Paradas do motor & 0 & 2 & 0 & 1 & 2 & 5 & 2 \\
\hline $1^{a}$ parada (minutos) & - & 38 & - & 10 & 43 & 15 & 4 \\
\hline $2^{\mathrm{a}}$ parada (minutos) & - & 22 & - & - & 24 & 30 & 15 \\
\hline $3^{\mathrm{a}}$ parada (minutos) & - & - & - & - & - & 39 & - \\
\hline $4^{\mathrm{a}}$ parada (minutos) & - & - & - & - & - & 62 & - \\
\hline $5^{\text {a }}$ parada (minutos) & - & - & - & - & - & 65 & - \\
\hline Retomada (minutos) & 91 & 96 & 74 & 155 & 75 & 172 & 125 \\
\hline
\end{tabular}




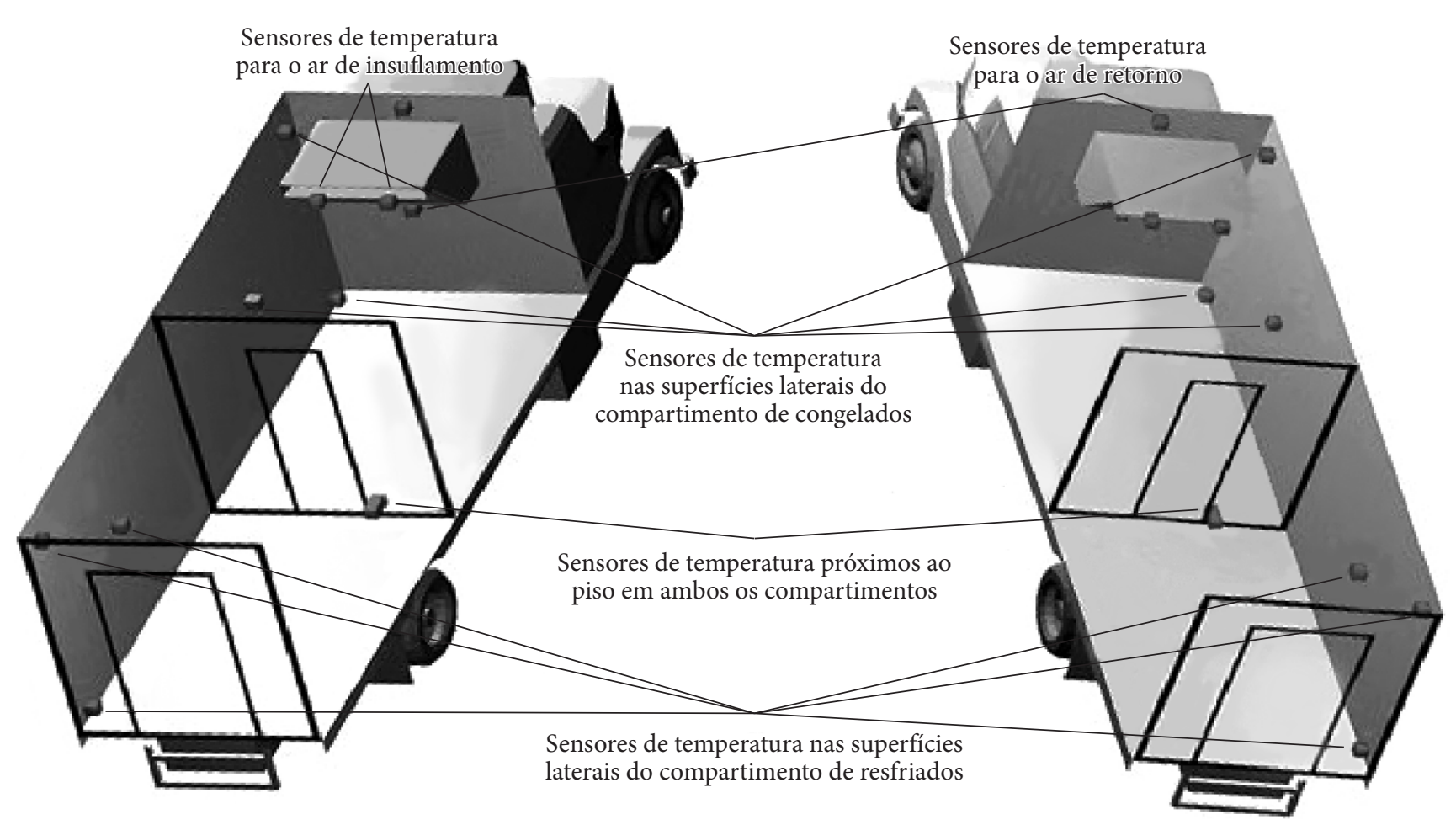

Figura 4. Sensores de temperatura nas superfícies internas da câmara frigorífica (laterais), próximos ao piso e ao evaporador.

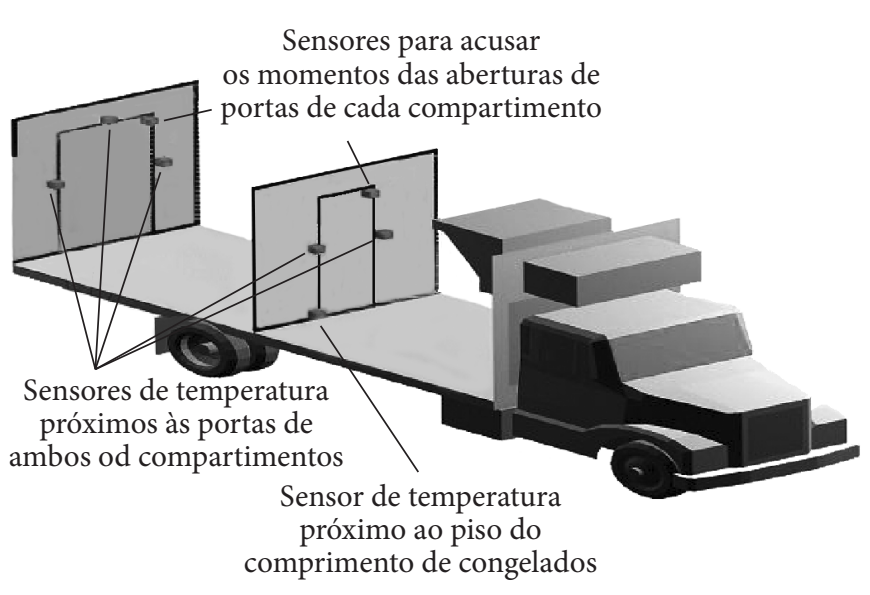

Figura 5. Sensores de temperatura próximos às portas da câmara frigorífica.

uma entrega de 30,83 minutos. No sétimo dia observou-se uma entrega de 8,25 minutos.

Quanto maior o número de entregas (maior o número de abertura de portas), maior a entrada de ar quente e úmido proveniente do ambiente externo. Assim, mais vapor de água é condensado e congelado na serpentina do evaporador, o que aumenta a necessidade da realização de degelos. Porém, o processo de degelo era temporizado para ocorrer a cada duas horas, independentemente do grau de necessidade de realização do degelo na serpentina do evaporador.
Os sensores instalados no sistema de refrigeração foram usados para identificar os momentos exatos em que os degelos por gás quente ocorreram ao longo dos dias monitorados. Observaram-se as variações da pressão do refrigerante registradas pelo sensor instalado após a válvula de expansão. Estes momentos foram evidenciados pelas elevações bruscas de pressões neste ponto, quando a pressão atingia valores próximos aos registrados pelo sensor de pressão colocado após a saída do condensador. Os momentos dos degelos por gás quente puderam ser evidenciados também pelo aumento de temperatura registrado pelo termopar instalado após a válvula de expansão.

$\mathrm{Na}$ Tabela 1 estão indicadas as quantidades de paradas do motor do caminhão e o tempo de permanência nesta condição em cada dia monitorado. Observou-se que algumas paradas do motor ocorreram durante a espera pela autorização para o início das entregas, enquanto o caminhão permanecia estacionado próximo ao estabelecimento comercial que iria receber as mercadorias. Esta prática frequente ocorria devido ao interesse do motorista do caminhão em economizar combustível durante estes momentos ociosos e foi observada no segundo dia ( $2^{\mathrm{a}}$ parada), no quinto dia ( $1^{\mathrm{a}}$ parada) e no sexto dia ( $3^{\mathrm{a}}$ e $4^{\mathrm{a}}$ paradas). As demais paradas foram realizadas durante as entregas.

O tempo de retomada da temperatura do ar do ambiente interno da câmara pelo sistema de refrigeração entre o término da última entrega e a chegada ao centro de distribuição em cada dia de monitoração também está indicado na Tabela 1.

A Figura 6 mostra, para cada dia de monitoração, a diferença entre a temperatura média ao final do dia (retorno ao 
centro de distribuição) e a temperatura média no início do dia. A duração da monitoração em cada dia também está indicada nesta figura.

Verifica-se que em nenhum dos dias monitorados o sistema de refrigeração foi capaz de reduzir plenamente as temperaturas internas de todos os pontos da câmara para os valores verificados inicialmente (antes da entrada da carga térmica devido às aberturas das portas). Isto demonstra que o sistema de refrigeração utilizado na câmara frigorífica para transporte não possui capacidade instantânea suficiente para atuar na redução das temperaturas internas após o final das entregas. Isto foi verificado principalmente no compartimento de resfriados.

Assim, foi concluído que o compartimento de resfriados desempenhou um efeito similar a uma antecâmara para o compartimento de congelados, pois, durante as entregas, parte da carga térmica proveniente do ambiente externo era retirada no ambiente de resfriados, de modo que, quando o ar entrava no compartimento de congelados, o impacto neste último era menor.

Foi observado um efeito acumulativo de aumento da temperatura do ambiente interno da câmara durante as entregas nos dias com mais aberturas de porta (quarto e sétimo dias), quando não havia tempo suficiente para o sistema de refrigeração atuar na redução da temperatura interna entre uma entrega e outra. Assim, sempre que uma nova entrega ocorria, esta contribuía com um novo aumento na temperatura interna da câmara. No quarto dia de monitoração, quando foram efetuadas 28 entregas, foram registradas as temperaturas máximas de $18,9^{\circ} \mathrm{C}$ para o compartimento de resfriados e de $9,2^{\circ} \mathrm{C}$ para o de congelados.

Observou-se que, além da existência do efeito acumulativo de aumento da temperatura do ar do ambiente refrigerado durante as entregas, as diferenças das médias das temperaturas registradas entre a chegada do caminhão ao centro de distribuição ao final do dia de entregas e o momento imediatamente anterior à primeira abertura de portas, no início do dia, ocorreram devido ao somatório de outros fatores, que são citados a seguir:

- Duração das entregas - nas entregas de longa duração, a carga térmica proveniente do ambiente externo dificultou o trabalho do sistema de refrigeração durante as retomadas de temperatura. Na Figura 7, observa-se que após a primeira entrega do quinto dia de monitoração, que teve a duração de 70 minutos, o sistema de refrigeração não foi capaz de reduzir a temperatura do ambiente de resfriados para os valores registrados antes da abertura da porta, mesmo tendo 34 minutos para a retomada.

- Parada do motor do caminhão durante os momentos de espera pela liberação do descarregamento nos estabelecimentos comerciais - prática observada algumas vezes nos dias de monitoração. No quinto dia, mesmo com a ocorrência de apenas duas entregas, a ação do sistema de refrigeração durante a retomada das temperaturas internas ao final do dia foi prejudicada, pois o motor do caminhão ficou desligado continuamente por 43 minutos durante a espera pelo início da segunda entrega, conforme mostrado na Figura 7.

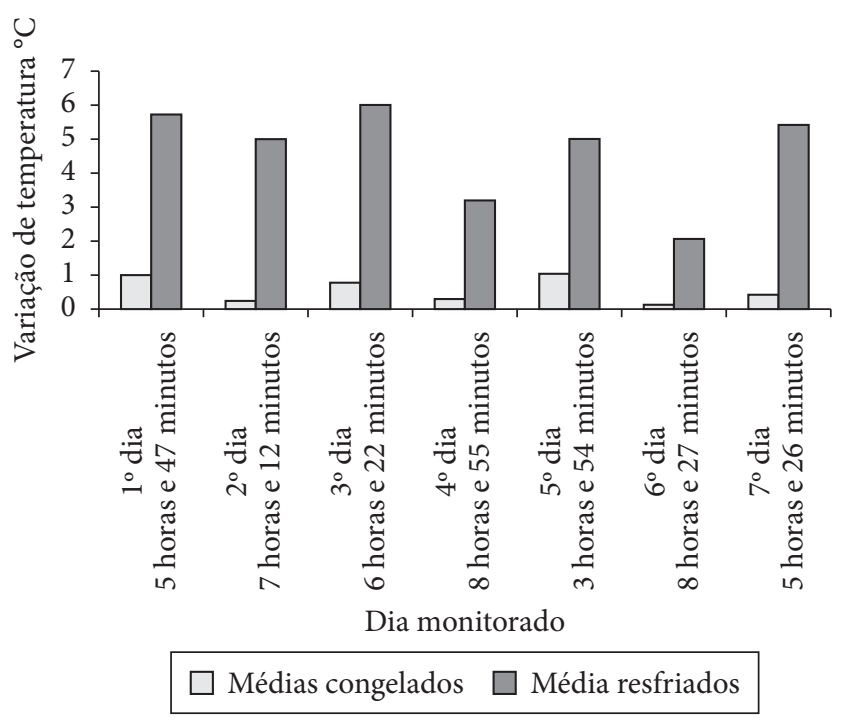

Figura 6. Diferença entre a temperatura média ao final do dia (retorno ao centro de distribuição) e a temperatura média no início do dia para cada dia monitorado.

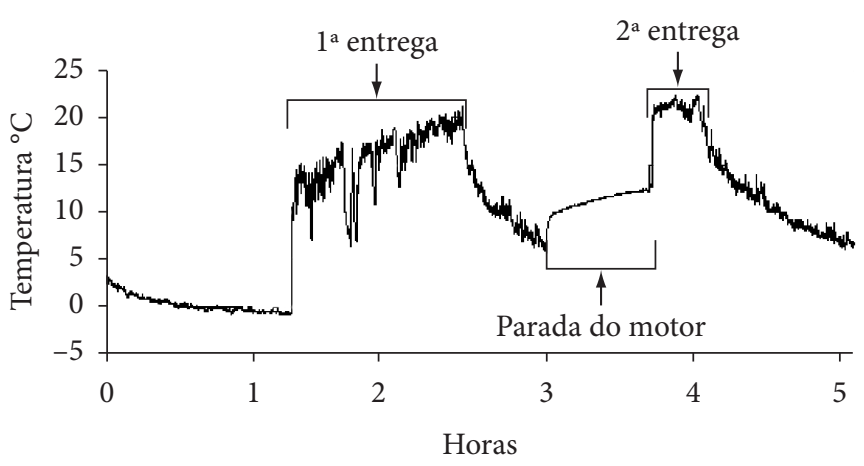

Figura 7. Histórico de variação de temperatura registrado próximo à porta do compartimento de resfriados no quinto dia de monitoração.

- Realização das entregas com o motor do caminhão desligado - esta prática é considerada correta, pois evita a troca excessiva de ar entre os ambientes interno e externo durante as aberturas de porta da câmara. Este procedimento foi verificado em todas as entregas do sexto dia de monitoração, dia que apresentou a menor diferença das médias das temperaturas entre a chegada do caminhão ao centro de distribuição ao final do dia de entregas e o momento imediatamente anterior à primeira abertura de portas, no início do dia. A Figura 8 mostra o histórico de temperatura do sexto dia de monitoração, registrado próximo à porta do compartimento de resfriados. As cinco paradas do motor do caminhão estão indicadas.

- Tempo disponível para a retomada das temperaturas pelo sistema de refrigeração entre o final da última entrega do dia e a chegada ao centro de distribuição nestes períodos em que as portas permaneceram fechadas e com a câmara vazia, o sistema pôde atuar na redução 


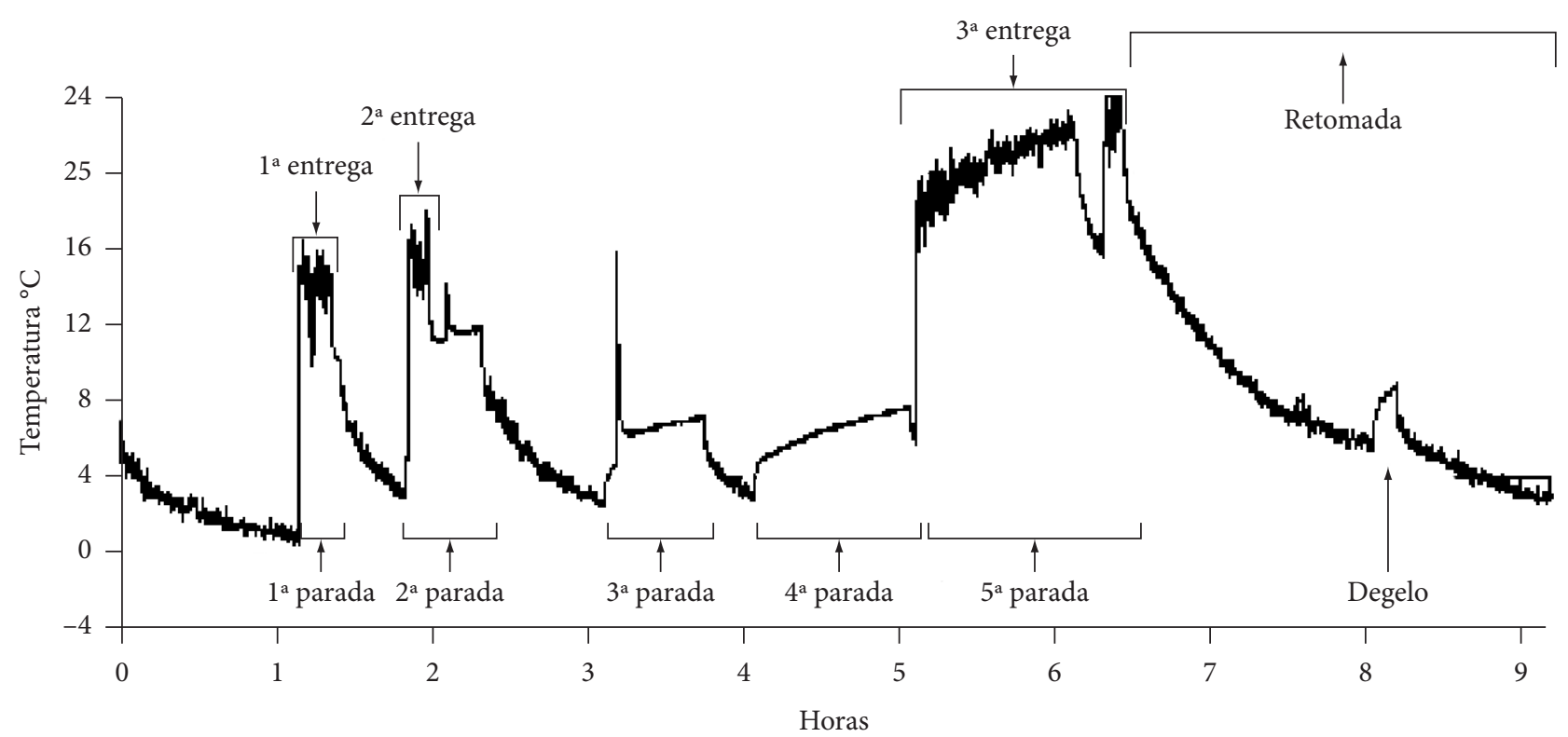

Figura 8. Histórico de variação de temperatura registrado próximo à porta do compartimento de resfriados no sexto dia de monitoração.

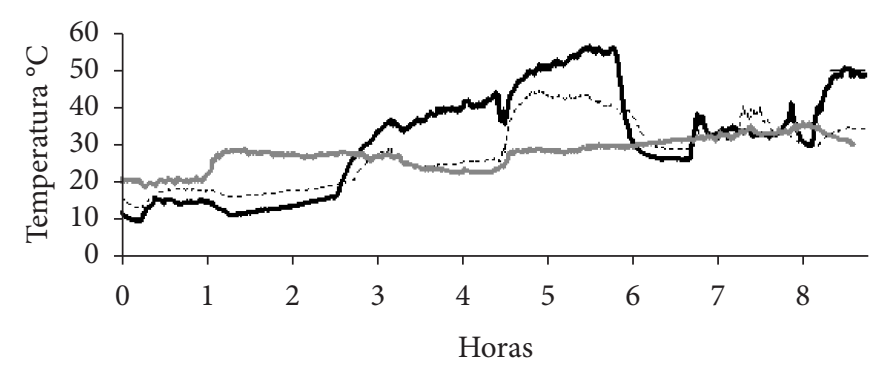

- Teto da carroceria _. Piso da carroceria
Superfície traseira da carroceria

Figura 9. Histórico das temperaturas das superfícies externas da câmara no primeiro dia de entregas.

das temperaturas internas. Os dois dias que tiveram o maior tempo para a retomada das temperaturas após o final das entregas foram o quarto dia (155 minutos) e o sexto dia (172 minutos), justamente os que apresentaram as menores variações de temperatura. Na Figura 8, o tempo disponível para a retomada de temperaturas no sexto dia pode ser visualizado.

Externamente, os dados registrados pelos sensores de temperatura indicaram duas situações distintas:

- Enquanto o caminhão se encontrava em deslocamento na rodovia durante o trajeto entre o centro de distribuição da empresa produtora dos alimentos e o local do primeiro estabelecimento comercial que iria receber as mercadorias, a superfície que apresentou a maior temperatura foi a do piso da câmara. Isto se deve à influência do asfalto e do ar quente proveniente do motor do caminhão, os quais aqueceram a superfície durante o deslocamento do caminhão pela rodovia.

- Enquanto o caminhão se encontrava parado durante as entregas, a câmara ficava exposta diretamente ao sol e, não havendo circulação de ar externo suficiente para auxiliar na redução da temperatura das superfícies externas da câmara, as que recebiam a maior incidência de radiação solar eram as superfícies que apresentavam as maiores temperaturas. Isto foi verificado com as superfícies do teto e da traseira da câmara, que apresentaram, respectivamente, temperaturas superiores a 50 e $40^{\circ} \mathrm{C} \mathrm{em}$ todos os dias monitorados. A Figura 9 mostra estas duas situações distintas.

Na Figura 9 observa-se que durante o período em que a câmara permaneceu na rodovia no percurso entre o centro de distribuição e o local da primeira entrega do primeiro dia de monitoração, a superfície que apresentou a maior temperatura foi a do piso da câmara. Isto foi verificado até aproximadamente 2 horas e 30 minutos. A partir deste momento, o caminhão começou a realizar as entregas dentro da cidade e as superfícies externas que apresentaram as maiores temperaturas foram a do teto e a da traseira da câmara.

\section{Conclusões}

Os resultados obtidos nas monitorações permitem concluir que:

- As aberturas das portas durante as entregas resultaram na entrada de carga térmica do ambiente externo que elevou a temperatura interna da câmara para valores muito acima dos valores de set-point. No compartimento de resfriados, que possuía valor de set-point de $0{ }^{\circ} \mathrm{C}$, em todos os dias monitorados, a temperatura do ar ultrapassou $+14^{\circ} \mathrm{C}$. No compartimento de congelados, o valor de set-point era de 
$-18{ }^{\circ} \mathrm{C}$ e em todos os dias a temperatura atingiu valores superiores $\mathrm{a}+7^{\circ} \mathrm{C}$.

- Nos dias em que o número de entregas foi grande (quarto e sétimo dias), observou-se um efeito acumulativo de aumento da temperatura interna na câmara frigorífica, principalmente no compartimento de resfriados, quando o sistema de refrigeração não possuía capacidade instantânea suficiente para retomar a temperatura de set-point.

- A parada do motor do caminhão durante os momentos de espera pela autorização do descarregamento dos produtos elevou a temperatura interna da câmara a valores críticos.

- O compartimento de resfriados atua como uma antecâmara para o compartimento de congelados.

- A superfície do piso, externamente, apresentou a temperatura mais elevada dentre as superfícies externas da câmara durante o deslocamento do caminhão pela rodovia.

\section{Agradecimentos}

Ao CNPq pela bolsa de mestrado;

À FAPESP que, através da linha PIPE, disponibilizou a verba necessária para a aquisição dos materiais de trabalho.

\section{Referências bibliográficas}

ASSOCIAÇÃO BRASILEIRA DE NORMAS TÉCNICAS - ABNT. NBR 14701. Transporte de produtos alimentícios refrigerados: procedimentos e critérios de temperatura. Rio de Janeiro, 2001. 7 p.

ESTRADA-FLORES, S.; EDDY, A. Thermal performance indicators for refrigerated road vehicles. International Journal of Refrigeration, v. 29 , n. 6, p. 889-898, 2006.

HEAP, R. D. Cold chain performance issues now and in the future. Bulletin of the IIR, n. 4, p. 1-11, 2006.

HEAP, R.; KIERSTAN, M.; FORD, G. Food transportation. Londres: Blackie Academic \& Professional, 1998.

HIRA, R. Manual de transporte frigorificado. São Paulo: Thermoking, 2001. 78 p.

INTERNATIONAL INSTITUTE OF REFRIGERATION - IIR. Recommendations for the processing and handling of frozen foods. Paris, $1986.418 \mathrm{p}$.

INTERNATIONAL INSTITUTE OF REFRIGERATION - IIR. Recommendations of the IIR on the quick-frozen-foods cold chain: quick-freezer design and construction, cold stores, transport, retail. Paris, 2006. 11 p.

INTERNATIONAL INSTITUTE OF REFRIGERATION - IIR. Temperature indicators and time-temperature integrators: 3rd informatory note on refrigeration and food. Paris, 2004. 3 p.

MERCANTILA. Guide to food transport: fruit and vegetables. Copenhagen, 1989.

NEVES FILHO, L. C. Refrigeração e alimentos. Campinas: UNICAMP, 2004.

TRESSLER, D. K. The freezing preservation of foods. Westport: Avi, 1968. (v. 1) 